\title{
MRI Evaluation of Low Back Ache Cases with Radiologic Evidence of Degenerative Lumbar Spine
}

\author{
Mishal Mohammed', Sunil M², Y Thiruvarul ${ }^{3}$ \\ ${ }^{1}$ Associate Professor, Department of Radiodiagnosis, Karuna Medical College, Vilayodi, Chittoor, Palakkad, Kerala, ${ }^{2}$ Associate Professor, Department of \\ Radiodiagnosis, Al Azhar Medical College and Superspeciality hospital, Thodupuzha, ${ }^{3}$ Professor, Department of Radiodiagnosis, Rajah Muthiah Medical College,
} Chidambaram.

\section{Abstract}

Background: Back pain is one of the leading cause of occupational disability and limiting factor in performing activities of daily living.Identifying the exact cause of low back ache is a tedious task, but is critical in planning the management of the condition. Magnetic resonance imaging is regarded as the most sensitive method in pointing out the exact pathology. Objective: To describe the MRI findings in patients with low back ache with radiologic evidence of degenerative lumbar spine. Subjects and Methods: A descriptive study was conducted among 80 patients who were sent for MRI evaluation, from Orthopedics and General Medicine department, with low back ache and radiographic evidence of degenerative changes of the lumbar spine. MRI was taken in all study subjects and the findings were noted. The data thus collected was properly coded and entered in Microsoft Excel and analysis was done using the software SPSS version 16.0. Results: Mean age of the study population was 51.46 years $(\mathrm{SD}=12.58$ years and majority $(73.75 \%)$ were males. Most common associated clinical findings was radicular pain syndrome $(36.25 \%)$ followed by weakness of lower limbs(18.75\%).MRI demonstrated following findings: dehydrative changes $(86.25 \%$ ), reduction in disc space $(67 \%)$, disc protrusion(36.25\%), disc extrusion(6\%), disc bulge(56\%), spondylolisthesis (18.75\%),spinal stenosis(7.5\%),Schmorl's nodes(4\%), hemangioma (2.5\%) and vertebral body destruction (1.25\%). Conclusion: Dehydrative changes and reduction of disc space were the most common MRI findings. Disc protrusion, disc extrusion as well was disc bulge was most commonly seen at L4-L5 level while spondylolisthesis was common at L5-S1 level.

Keywords: Low back ache, Disc protrusion, Disc bulge, Spondylolisthesis.

Corresponding Author: Dr Sunil M, Associate Professor, Department of Radio diagnosis, Al Azhar Medical College and Super Specialty hospital, Thodupuzha.

Received: February 2019

Accepted: February 2019

\section{Introduction}

Low backache is a major cause of acute and chronic disability in the adult population. Between $60-80 \%$ of adults suffer from low backache some time in their lives. ${ }^{[1]}$ Pain can originate from the bones, joints, ligaments, muscles, nerves, inter vertebral discs as well as paravertebral tissues. Various causes for low back ache includes spondylosis, inter vertebral disc prolapse, spondylolysis, spondylolisthesis, sacroiliac strain, spina bifida, sacralisation of L5 vertebra, lumbarization of S1 vertebra, hemangioma and infections of spine. ${ }^{[2]}$ Identifying the specific cause in each case is a confounding problem for the treating physician and imaging modalities have played a huge role in solving this dilemma. Initially, plain x-ray and myelography was the only modality of radiological investigation available to categorize the cause of low backache. This was followed by the introduction of CT and CT myelogram, but the use was limited by the inability to demonstrate thecal sac and nerve roots separate from the disc. With the introduction of MRI, a major leap was achieved in delineating the cause of low backache. MRI being noninvasive has the added advantage of distinguishing bone, disc, ligament, nerve, thecal sac and spinal cord better than CT. In addition to this, with the advent of surface coils, fast scan sequences, phase array technology and 3D acquisition, the spatial and contrast resolution of MR images of spine has improved thus making the diagnosis more accurate. 3 Hence this study was conducted with objective of describing the MRI findings in patients with low back ache with radiologic evidence of degenerative lumbar spine.

\section{Subjects and Methods}

After getting approval from the Institutional ethical committee, a descriptive study was conducted in the Department of Radio diagnosis, RMMCH, Chidambaram, among 80 patients with low back ache, who were having radiographic evidence of degenerative changes of the lumbar spine, during the period April 2011 to October 2012.

\section{Sample Size:}

In a study conducted by Nirmalkumar $\mathrm{G}$ et al assessing the pathology of low back ache using MRI, degenerative disc 
disease changes was observed in $79.5 \% .{ }^{[4]}$ Using this data minimum sample required for the current study was calculated using the formula

\section{$\mathrm{n}=\mathrm{Z} \alpha^{2} \mathrm{PQ}$,}

taking ' $d$ ' as $9 \%$ which is less than $20 \%$ of $P, n=78$.

Hence this study was conducted among 80 patients with low back ache, who were having radiographic evidence of degenerative changes of the lumbar spine.

\section{Sampling Technique:}

80 consecutive, consenting patients with low back ache, who were having radiographic evidence of degenerative changes of the lumbar spine, referred from Department of Orthopedics and General Medicine, RMMCH, Chidambaram were recruited into the study.

\section{Study Procedure:}

After getting approval from the Institutional ethical committee and Head of the department- Radio diagnosis, $\mathrm{RMMCH}$, Chidambaram, a descriptive study was conducted among 80 patients who were sent for MRI evaluation, from Orthopedics and General Medicine department, with low back ache and radiographic evidence of degenerative changes of the lumbar spine. Informed consent was taken from all the study participant after excluding those with history of chronic infection/ trauma/ congenital anomalies of spine/ Spinal surgery. Detailed history of the patient were recorded and plain $X$ ray of spine was evaluated. MRI of spine was done using Philips Intera 1.5T R11 with pulsar gradient system. Patients were imaged with synergy spine surface coil using FOV $320 \mathrm{~mm}$ and the following sequences were studied- Sagittal T1, Sagittal FSE T2, Axial 'I'1, Axial FSE' 'T2 and Sagittal S'IIR sequence.

\section{Statistical Analysis:}

The data was properly coded and entered in Microsoft Excel. Further analysis was done using the software SPSS version 16.0. Qualitative variables were expressed as percentages and quantitative as mean with standard deviation.

\section{Results}

The study sample consisted of among 80 patients with low back ache, who were having radiographic evidence of degenerative changes of the lumbar spine. Mean age of the study population was 51.46 years $(\mathrm{SD}=12.58$ years $)$. Study population consisted of 59 males $(73.75 \%)$ and 21 females (26.25\%).In addition to low back ache other common clinical findings included radicular pain syndrome $(36.25 \%)$, weakness of lower $\operatorname{limbs}(18.75 \%)$, paresthesia(7.5\%) and diminished reflexes (2.5\%).Plain radiography (X ray) of the cases revealed osteophytes in $83.7 \%$, joint space reduction in $58.7 \%$, vacuum phenomenon in $3.75 \%$ and end plate sclerosis in $2.5 \%$

MRI examination revealed dehydrative changes in lumbar spine in 69 patients $(86.25 \%)$. The commonest site for dehydrative changes was found to be L4-L5 vertebra (50\%)

followed by L5-S1 level (46.25\%) and L3-L4 level $(41.25 \%)$. Dehydrative changes without bulge were seen in 24 patients $(30 \%)$ which is the earliest sign of a degenerative disc. Among the patients showing degenerative changes majority $(72 \%)$ belonged to $21-30$ years.

$67 \%$ of the study subjects showed a reduction in disc space and it was most common in L4-L5 level (50\%) followed by L5-S1 level (45\%) and L4-L3 level (40\%).

Disc bulge was observed in 45 out of 80 patients (56\%) and the maximum number of cases $(40 \%)$ were seen in $31-40$ years age group. Disc bulge was seen slightly higher in females $(57.14 \%)$ when compared to males $(55.9 \%)$. Disc bulge was also most commonly seen at L4-L5 level (41.25\%) followed by L5-S1 level (36.25\%), L3-L4 level $(23.75 \%)$ and L2-L3 level (18.75\%).

Disc protrusion was seen in $36.25 \%$ of cases and most common age group showing disc protrusion was 41-50 years $(31.03 \%)$. Similar to disc bulge, disc protrusion was also most common at L4-L5 level (60\%) followed by L5-S1 and L3-L4 levels (16.7\% each). $75.8 \%$ cases of disc protrusion were centrolateral and $24.2 \%$ cases were central. Left centrolateral $(77.3 \%)$ was more common than right centrolateral $(22.7 \%) .63 \%$ of patients with radiculopathy showed disc protrusion

On the other hand disc extrusion was observed in $6 \%$ of subjects and all of them were males. $80 \%$ of disc extrusion was noted at L4-L5 level and $20 \%$ at L5-S1 level. Current study could not demonstrate sequestration in any of the cases.

Spinal stenosis was seen in $7.5 \%$ of patients, most of them in 51-60 year age group (66.7\%). Vertebral body end plate changes were seen in 10 patients $(8 \%), 2.5 \%$ showed grade I changes whereas grade II and grade III changes were shown by $5 \%$ each.

None of the cases showed PLL hypertrophy whereas 3.75\% showed Ligamentum flavum hypertrophy and 5\% showed facet hypertrophy. Spondylolisthesis was identified in $18.75 \%$ of patients, $66.7 \%$ at L5-S1 level and $33.3 \%$ at L4L5 level.

In addition to these findings, focal vertebral body changes were seen in $10 \%$ of subjects, Schmorl's nodes in $4 \%$ of subjects, hemangioma $2.5 \%$ of subjects and vertebral body destruction in $1.25 \%$ of study subjects.

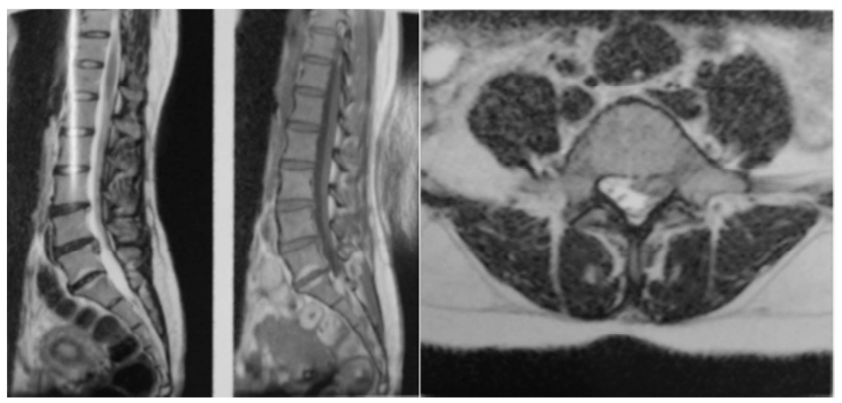

Figure 1: Sagittal T1 \& T2 MR images showing extrusion at L4-L5 disc and protrusion at L3-L4 disc. There is associated Modic type 2 changes at L5 and S1 vertebral bodies. Axial MR showing extruded disc distorting thecal sac. 


Table 1: Distribution of study subjects based on associated
symptoms
\begin{tabular}{|c|c|}
\hline Symptoms & No. of cases \\
\hline Radicular pain syndrome & $29(36.25 \%)$ \\
\hline Weakness of lower limbs & $15(18.75 \%)$ \\
\hline Paresthesia & $6(7.5 \%)$ \\
\hline Diminished reflexes & $2(2.5 \%)$ \\
\hline
\end{tabular}

Table 2: Distribution of study subjects according to the abnormalities detected on MRI

\begin{tabular}{|c|c|}
\hline Abnormality & No of cases (\%) \\
\hline Dehydrative changes & $86.25 \%$ \\
\hline Reduction in disc space & $67 \%$ \\
\hline Disc protrusion & $36.25 \%$ \\
\hline Disc bulge & $56 \%$ \\
\hline Spondylolisthesis, & $18.75 \%$ \\
\hline Spinal stenosis & $7.5 \%$ \\
\hline Disc extrusion & $6 \%$ \\
\hline Schmorl's nodes & $4 \%$ \\
\hline Hemangioma & $2.5 \%$ \\
\hline Vertebral body destruction & $1.25 \%$ \\
\hline
\end{tabular}

Table 3: Distribution of study subjects according to the anatomical location of abnormalities detected on MRI

\begin{tabular}{|c|c|c|c|c|c|c|}
\hline \multirow{2}{*}{$\begin{array}{c}\text { Abnormality } \\
\text { detected }\end{array}$} & $\begin{array}{c}\text { No of cases at each anatomical location } \\
\text { L1 }\end{array}$ & L1-2 & L2-3 & L3-4 & L4-5 & $\begin{array}{c}\text { L5- } \\
\text { S1 }\end{array}$ \\
\hline $\begin{array}{c}\text { Dehydrative } \\
\text { Changes }\end{array}$ & 4 & 8 & 12 & 33 & 40 & 37 \\
\hline Disc space reduction & 2 & 7 & 11 & 32 & 40 & 36 \\
\hline Disc Bulge & 3 & 7 & 15 & 23 & 33 & 29 \\
\hline Disc extrusion & 0 & 0 & 0 & 0 & 4 & 0 \\
\hline Disc protrusion & 0 & 0 & 2 & 5 & 18 & 4 \\
\hline
\end{tabular}

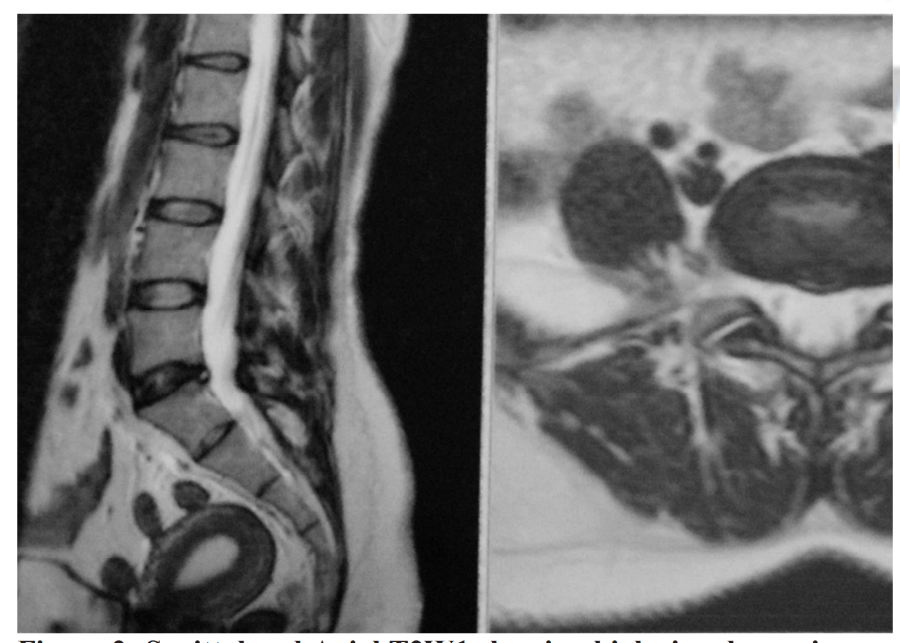

Figure 2: Sagittal and Axial T2W1 showing high signal zone in annulus at midline of L5-S1 disc suggestive of annular tear.

\section{Discussion}

This study was conducted in 80 patients with low back ache and radiographic evidence of degenerative disease of lumbar spine. The mean age of the study population was 51.46 years $(\mathrm{SD}=12.58$ years) and $73.75 \%$ were males. Similar results were also shown by Miller et al as well as de Schepper et al. ${ }^{[5,6]}$ The increased incidence of low backache in males may be because of increased physical activity and more involvement in sports and laborious work resulting in mechanical stress.

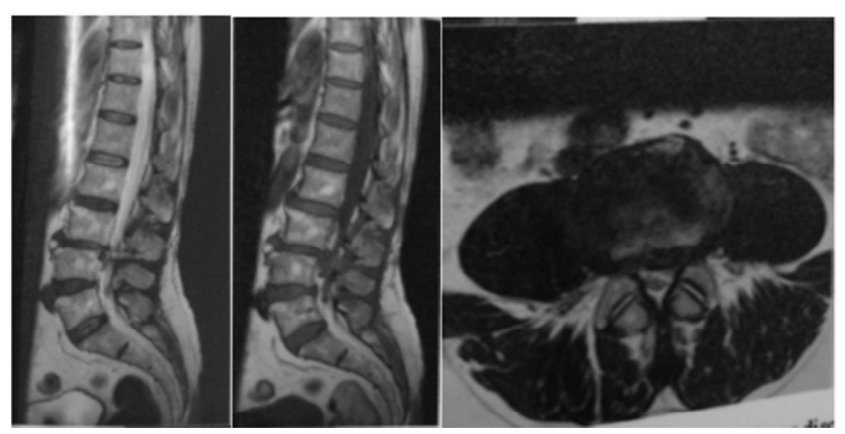

Figure 3: Sagittal T1 \& T2 weighted MR images showing large disc extrusion at L3-L4 disc causing canal stenosis. Protrusion at L4-L5, L5-S1 disc and type 2 Modic changes noted. Axial T2W1 showing extrusion impinging thecal sac.

Symptoms at presentation were similar to the classical symptoms of lumbar disc degeneration as described by Taher et al. ${ }^{[7]}$ In addition to the low back ache the most common symptom was radicular pain.

An x-ray of the spine is usually the first diagnostic tool used in evaluating back pain and it helps in the analysis of the individual bones of the spine and the overall contour of the spinal column. ${ }^{[8]}$ All study subjects showed degenerative changes on plain radiography and the most common finding was the presence of osteophytes and reduction in joint space. Similar findings were also reported by Sultana et al. ${ }^{[9]}$

MRI is now regarded as the standard imaging modality for detecting disc pathology due to its advantage of lack of radiation, multiplanar imaging capability, excellent spinal soft-tissue contrast and precise localization of intervertebral discs changes. ${ }^{[10,11]}$ Dehydrative changes, which is one of the earliest signs of disc degeneration, seen as a loss of signal intensity in the nucleus pulposus on T2W1 was found in 69 patients commonly at L4-L5 vertebra. These findings were similar to those reported by Erkintalo et al who found Dehydrative changes in the nucleus pulposus to be closely associated with early development of degenerative disc changes. $^{[12]}$

Disc space reduction and disc bugle was observed in $67 \%$ and $56 \%$ of the study subjects respectively and the most common site was L4-L5 level in both cases. Similar findings were reported by G Jarvik and Deyo. ${ }^{[13]}$

Disc Protrusion which was observed in $30 \%$ of study subjects was found to be more common in patients who presented with radiculopathy. Our findings matched with the study by McCall who reported $26 \%$ incidence of the protrusion. ${ }^{[14]}$ On the other hand Jarvik et al and Videman et al observed a higher prevalence than current study. ${ }^{[13,15]}$ The study by Boos et al also revealed a higher incidence of protrusion and root compression with patients presenting with radiculopathy as in the current study. ${ }^{[16]}$

Disc extrusion was observed in $6 \%$ of study subjects which was same as that demonstrated by Jarwick et al. ${ }^{[13]}$ On the other hand lain et al (22) reported a higher incidence of 
$26 \%{ }^{[14]}$ Current study could not demonstrate sequestration in any of the cases while spinal stenosis was seen in $7.5 \%$ of the study subjects.

Vertebral body changes were seen in 10 patients $(8 \%)$ and the proportion of various grades were less when compared to Modic et al. ${ }^{[17]}$ Spondylolisthesis was demonstrated in $18.5 \%$ of patients and This matched the data presented by Nizard et al who found the incidence of Spondylolisthesis in both sex to be $19.7 \% .^{[18]}$

\section{Conclusion}

MRI because of its non-invasive nature and better imaging capabilities has proved to be the preferred imaging modality in demonstration of specific pathology of low backache. In the current study, conducted among 80 cases of low backache with radiographic evidence of degenerative lumbar spine majority were males. Dehydrative changes in lumbar spine were seen in $86.25 \%$ and reduction of disc space in $67 \%$.Disc protrusion, disc extrusion as well was disc bulge was most commonly seen at L4-L5 level while spondylolisthesis was common at L5-S1 level.

\section{Acknowledgments:}

The authors acknowledge the support received from the staff - Department of Radiodiagnosis, RMMCH, Chidambaram in the completion of the study. The hospitable nature and cooperation of the study participants are also acknowledged at this moment

\section{References}

1. Low Back Pain Fact Sheet National Institute of Neurological Disorders and Stroke [Internet]. [cited 2019 Feb 16]. Available from: https://www.ninds.nih.gov/Disorders/Patient-Caregiver-

Education/Fact-Sheets/Low-Back-Pain-Fact-Sheet

2. Allegri M, Montella S, Salici F, Valente A, Marchesini M, Compagnone $\mathrm{C}$, et al. Mechanisms of low back pain: a guide for diagnosis and therapy. F1000Research [Internet]. 2016 Oct 11;5. Available from: https://www.ncbi.nlm.nih.gov/pmc/articles/PMC4926733/

3. Vertinksy AT, Krasnokutsky MV, Augustin M, Bammer R. Cutting
Edge Imaging of THE Spine. Neuroimaging Clin N Am. 2007 Feb;17(1):117-36

4. Gopalakrishnan N, Nadhamuni K, Karthikeyan T. Categorization of Pathology Causing Low Back Pain using Magnetic Resonance Imaging (MRI). J Clin Diagn Res JCDR. 2015 Jan;9(1):TC17-20.

5. Miller JA, Schmatz C, Schultz AB. Lumbar disc degeneration correlation with age, sex, and spine level in 600 autopsy specimens Spine. 1988 Feb;13(2):173-8.

6. de Schepper EIT, Damen J, van Meurs JBJ, Ginai AZ, Popham M, Hofman A, et al. The association between lumbar disc degeneration and low back pain: the influence of age, gender, and individual radiographic features. Spine. 2010 Mar 1;35(5):531-6.

7. Taher F, Essig D, Lebl DR, Hughes AP, Sama AA, Cammisa FP, et al. Lumbar Degenerative Disc Disease: Current and Future Concepts of Diagnosis and Management. Adv Orthop [Internet]. 2012;2012 Available

https://www.ncbi.nlm.nih.gov/pmc/articles/PMC3335178/

8. Murphy WA, Preston BJ. Degenerative diseases of the spine, In: Adam A, editor. Grainger \& Allison's Diagnostic Radiology: A Text Book of Medical Imaging.4thedn. Churchill Livingstone:London; 2001.p. 2020.

9. Sultana et al. Plain Radiographic Evaluation of Degenerative Changes of Lumbosacral Spine-Correlation with Magnetic Resonance Imaging Findings. Faridpur Med Coll J 201510268-70.

10. Haughton V. Imaging intervertebral disc degeneration. J Bone Joint Surg Am. 2006;88 (Suppl 2):15-20.

11. Maravilla KR, Lesh P, Weinreb JC, Selby DK, Mooney V. Magnetic resonance imaging of the lumbar spine with CT correlation. AJNR Am J Neuroradiol. 1985;6(2):237-45.

12. Erkintalo MO, Salminen JJ, Alanen AM, Paajanen HE, Kormano MJ. Development of degenerative changes in the lumbar intervertebral disk: results of a prospective MR imaging study in adolescents with and without low-back pain. Radiology. 1995 Aug 1;196(2):529-33.

13. Jarvik JG, Deyo RA. Imaging of lumbar intervertebral disk degeneration and aging, excluding disk herniations. Radiol Clin North Am. 2000 Nov;38(6):1255-66, vi.

14. MCCALL IW. Lumbar herniated disks. Radiol Clin North Am 2000; 38: 1293-1309.

15. Videman T, Battié MC, Gill K, Manninen H, Gibbons LE, Fisher LD. Magnetic resonance imaging findings and their relationships in the thoracic and lumbar spine. Insights into the etiopathogenesis of spinal degeneration. Spine. 1995 Apr 15;20(8):928-35.

16. Boos N, Rieder R, Scade V. the Diagnostic accuracy of MR imaging, work perception and psychological factors in identifying symptomatic disc herniation. Spine $1995 ; 20: 2613-2625$.

17. Modic MT, Masaryk TJ, Ross JS, Carter JR. Imaging of degenerative disk disease. Radiology. 1988 Jul 1;168(1):177-86.

18. S Nizard R S, Wybier M, Laredo J D. Radiologic assessment of lumbar intervertebral instability and degenerative Spondylolisthesis. Radiology clinics of North America 2001; 39: 55-70.

Copyright: (C) the author(s), publisher. Asian Journal of Medical Radiological Research is an Official Publication of "Society for Health Care \& Research Development". It is an open-access article distributed under the terms of the Creative Commons Attribution Non-Commercial License, which permits unrestricted non-commercial use, distribution, and reproduction in any medium, provided the original work is properly cited.

How to cite this article: Mohammed M, Sunil M, Thiruvarul Y. MRI Evaluation of Low Back Ache Cases with Radiologic Evidence of Degenerative Lumbar Spine. Asian J. Med. Radiol. Res. 2019;7(1):16-19.

DOI: dx.doi.org/10.21276/ajmrr.2019.7.1.4

Source of Support: Nil, Conflict of Interest: None declared. 